PAPER \# E5/D4-4

\title{
FRICTION AND WEAR PERFORMANCE OF DIAMONDLIKE CARBON FILMS GROWN IN VARIOUS SOURCE GAS PLASMAS*
}
A. Erdemir, I. B. Nilufer ${ }^{a}$, O. L. Eryilmaz ${ }^{a}$, M. Beschliesser ${ }^{b}$, and G. R. Fenske Energy Technology Division
Argonne National Laboratory

Argonne, IL 60439

Revised, June 1999

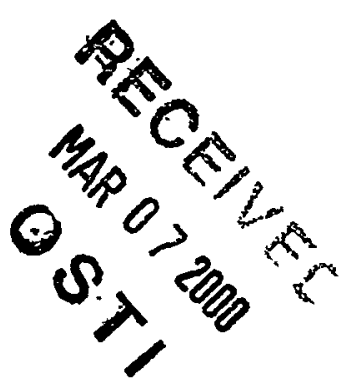

The submitted manuscript hos been authored by a
contractor of the U. S. Govemment under contract No.
W-31-109-ENG-38. Accordingly. the U. S. Govemument
retains a nonexelusive, royalty-free license to publish or
reproduce the published form of this contribution, or
allow others to do so, for U. S. Govemment purposes.

For presentation at International Conference on Metallurgical Coatings and Thin Films, April 12-16, 1999, San Diego, CÁ.

*Work supported by the U.S. Department of Energy under Contract W-31-109-Eng.-38.

${ }^{a}$ Permanent Address: Istanbul Technical University, Faculty of Metallurgical and Chemical Engineering, Istanbul, Turkey

${ }^{b}$ Department of Physical Metallurgy and Materials Testing, The University of Leoben, A - 8700 Leoben, Austria 


\section{DISCLAIMER}

This report was prepared as an account of work sponsored by an agency of the United States Government. Neither the United States Government nor any agency thereof, nor any of their employees, make any warranty, express or implied, or assumes any legal liability or responsibility for the accuracy, completeness, or usefulness of any information, apparatus, product, or process disclosed, or represents that its use would not infringe privately owned rights. Reference herein to any specific commercial product, process, or service by trade name, trademark, manufacturer, or otherwise does not necessarily constitute or imply its endorsement, recommendation, or favoring by the United States Government or any agency thereof. The views and opinions of authors expressed herein do not necessarily state or reflect those of the United States Government or any agency thereof. 


\section{DISCLAIMER}

Portions of this document may be illegible in electronic image products. Images are produced from the best available original document. 
PAPER \# E5/D4-4

\title{
FRICTION AND WEAR PERFORMANCE OF DIAMIONDLIKE CARBON FILMS GROWN IN VARIOUS SOURCE GAS PLASMAS
}

\author{
A. Erdemir, I. B. Nilufer, O. L. Eryilmaz, M. Beschliesser, and G. R. Fenske \\ Energy Technology Division \\ Argonne National Laboratory \\ Argonne, IL 60439
}

\begin{abstract}
In this study, we investigated the effects of various source gases (methane, ethane, ethylene, and acetylene) on the friction and wear performance of diamondlike carbon (DLC) films prepared in a plasma enhanced chemical vapor deposition (PECVD) system. Films were deposited on AISI H13 steel substrates and tested in a pin-on-disk machine against DLCcoated M50 balls in dry nitrogen. We found a close correlation between friction coefficient and source gas composition. Specifically, films grown in source gases with higher hydrogen-tocarbon ratios exhibited lower friction coefficients and higher wear resistance than films grown in source gases with lower hydrogen-to-carbon $(\mathrm{H} / \mathrm{C})$ ratios. The lowest friction coefficient (0.014) was achieved with a film derived from methane with an $\mathrm{H} / \mathrm{C}$ ratio of 4 , whereas the coefficient of films derived from acetylene $(H / C=1)$ was of 0.15 . Similar correlations were observed for wear rates. 'Specifically, films derived from gases with lower $\mathrm{H} / \mathrm{C}$ values were worn out and the substrate material was exposed, whereas films from methane and ethane remained intact and wore at rates that were nearly two orders of magnitude lower than films obtained from acetylene.
\end{abstract}


Key Words: friction, wear, diamondlike carbon, source gas chemistry

\section{INTRODUCTION}

Diamondlike carbon (DLC) films provide low friction and high wear resistance to slidingcontact interfaces, hence they are good prospects for a wide range of tribological applications. Some of the current and future tribological applications for these films are high-precision bearings, biomedical implants, mechanical seals, hard disks, microelectromechanical systems, gears, metal- and/or plastic-forming dies, etc. [1-3]. DLC films can be deposited at temperatures ranging from subzero to $300^{\circ} \mathrm{C}$ and at fairly high deposition rates by a variety of methods, including ion-beam deposition, $\mathrm{DC}$ and $\mathrm{RF}$ magnetron sputtering, arc-physical vapor deposition (arc-PVD), plasma-enhanced chemical vapor deposition (PECVD), and laser ablation [4-8]. Depending on the deposition method and carbon source, large amounts of hydrogen may be present within the amorphous structure of DLC films [1,3]. Films with very little or no hydrogen are also available and can be deposited by laser ablation and arc-PVD methods $[9,10]$. Recently, new procedures were developed to dope these coatings with several elements (e.g., nitrogen, silicon, tungsten, titanium, and niobium) to modify their structure and/or chemistry and thereby achieve better optical, electronic, or tribological properties [3,1113]. Briefly, the DLC films of today may look alike but they differ markedly in their properties.

Because of large differences in the microstructure and chemical states of DLC films, reported tribological data differ substantially from one paper to another. Furthermore, the tribological performance of these films is very sensitive to test conditions. Specifically, research data have shown that the friction and wear coefficients of these films differ substantially when tested in differing environments or at high temperatures. Other test parameters (such as load, speed, counterface material, and temperature) were also shown to influence the tribological behavior of DLC films [13-17]. Certain DLC films exhibited high friction and wear in humid test environments whereas others were less sensitive to ambient humidity. The presence of some dopants (e.g., silicon) in their structures appears to make these films less sensitive to humidity 
[13]. The performance of hydrogen-free DLC films is better in moist air, but hydrogenated DLCs provide much lower friction and wear in dry and inert test environments [18-23]. For most DLC films, exposure to high temperatures may cause irreversible chemical and structural changes that can, in turn, lead to high friction and wear $[17,24]$. At $300^{\circ} \mathrm{C}$ and above, DLC films gradually turn into graphite and hence wear out quickly [24]. Certain dopants such as silicon, titanium, tungsten, may retard graphitization and hence stretch the durability of DLCs at elevated temperatures.

The goal of this study is to investigate the effects of source gas composition on the friction and wear performance of resultant DLC films. In an earlier study [25], it was shown that regardless of the deposition process, the initial gas composition from which the DLC films were derived, was the most critical factor that affected friction and wear. In this study, this observation is further explored in an effort to gain further insight into the very complex friction and wear mechanisms of DLC films. We hope that the results of this study will further the optimization of source gas composition and lead to much-improved friction and wear performance of future DLC films.

\section{EXPERIMENTAL PROCEDURES}

In this study, we used a PECVD method to produce DLC films on polished surfaces of AISI M50 balls and H13 steel'substrates. The film were about $1 \mu \mathrm{m}$ thick and were derived from methane $\left(\mathrm{CH}_{4}\right)$, acetylene $\left(\mathrm{C}_{2} \mathrm{H}_{2}\right)$, ethane $\left(\mathrm{C}_{2} \mathrm{H}_{6}\right)$, and ethylene $\left(\mathrm{C}_{2} \mathrm{H}_{4}\right)$ gases. The procedure for forming DLC films on steel substrates by PECVD involved sputter-cleaning of the substrates in an Ar plasma for $30 \mathrm{~min}$ by applying a 1200-1700 V bias. The substrates were then coated with a $50-70 \mathrm{~nm}$ thick silicon bond layer by switching to a sputtering mode and sputtering silicon from a target. In some cases, silane $\left(\mathrm{SiH}_{4}\right)$ gas was also used to form a bond layer on steel substrates. Finally, carbon-bearing source gases were bled into the chamber and the deposition of DLC on the substrates was started. The gas pressure varied between 10 and 13 mtorr and the RF bias was maintained at $1600 \mathrm{~V}$. Further details of the deposition process can 
be found in Ref. 25.

The samples were tested for friction and wear on a ball-on-disk tribometer, in a dry nitrogen environment under a $10 \mathrm{~N}$ load (which created a peak Hertz pressure of $1.04 \mathrm{Gpa}$ ) and at a velocity of $0.5 \mathrm{~m} / \mathrm{s}$ for a distance of $5 \mathrm{~km}$. To measure the friction coefficient of the DLC coating against itself, not against steel, AISI M50 steel balls ( $9.5 \mathrm{~mm}$ in diameter), also coated with DLC, used as the counterface material. The Vickers hardness of the substrates and balls was $\sim 8 \mathrm{GPa}$ and their surface roughness was better than $0.1 \mu \mathrm{m}$ centerline average (CLA). Each coating was tested twice in dry nitrogen ( $0 \%$ humidity). The test chamber was purged with dry nitrogen for at least two hours after $0 \%$ humidity was shown on a hygrometer display unit. Wear volume $\left(W_{b}\right)$ of the steel balls was determined with an optical microscope. Specifically, wear scar diameter and the diameter of the ball were used in the equation: $\mathrm{W}_{\mathrm{b}}=$ $3.14 d^{4} / 64 r$, where $r$ is the ball radius, $d$ is the diameter of the wear scar, and $W_{b}$ is the wear volume. To simplify the calculations, we assumed that the wear scar was flat.

\section{EXPERIMENTAL RESULTS}

The Raman spectra of the films derived from various source gases revealed broad peaks that were centered at $\sim 1560 \mathrm{~cm}^{-1}$ and shouldered peaks at $\sim 1350 \mathrm{~cm}^{-1}$. The shouldered peaks were somewhat less pronounced on films produced in acetylene and ethane plasmas. Overall, the films displayed Raman féatures typical of DLC films and were consistent with the Raman spectra presented elsewhere $[1,26,27]$.

Figure 1 shows the frictional performance of DLC films derived from various source gases.

The values in this figure are based on the average of the steady-state portion of the actual frictional traces. As is clear, the friction coefficient of the film grown in acetylene was the highest and the frictional trace of this test pair (Fig. 2) was rather unsteady. After the tests, we noticed that the film was worn out on the ball side and that the M50 steel was slightly exposed. The later portion of the frictional trace (see Fig. 2) of the film grown in an acetylene plasma 
may have been due to the M50 steel sliding against the DLC film. This observation on acetylene-grown films is consistent with the results of an earlier study during which acetylenegrown films had shown a very high and erratic friction coefficient when tested against uncoated steel balls in dry nitrogen. DLC films grown in ethylene exhibited relatively lower (i.e., 0.08) friction coefficients at steady states, whereas the DLC films grown in ethane and methane exhibited much lower friction coefficients (i.e., 0.04 and 0.014 , respectively; see Fig.2). In Fig.2, the frictional trace of the ethane-grown film is much smoother than that of the acetylene-grown film. The friction coefficient of an uncoated M50 ball against the H13 steel disk in dry nitrogen was $\sim 0.8$.

The wear rates of DLC-coated M50 balls during sliding against DLC-coated H13 disks in dry nitrogen are shown in Fig.3. These rates show a similar trend to that of the friction results presented in Fig. 1. Specifically, test data show that balls coated with acetylene-grown films suffer the most wear (i.e., $7.5 \times 10^{-7} \mathrm{~mm}^{3} / \mathrm{N}$.m), whereas those balls coated with methanegrown films suffer the least wear (i.e., $9 \times 10^{-9} \mathrm{~mm}^{3} / \mathrm{N}$.m). The wear rate of an uncoated M50 ball against the uncoated $\mathrm{H} 13$ disk was $4.6 \times 10^{-6} \mathrm{~mm}^{3} / \mathrm{N} . \mathrm{m}$ when tested under the same conditions. The wear rates of balls coated with ethylene- or ethane- grown DLC films were moderate, but still significantly higher than those of the balls coated with a methane-grown DLC film.

\section{DISCUSSION}

The wear resistance of the DLC films is mainly attributed to their high mechanical strength and hardness [1-4] whereas their low friction is not yet been fully-understood. However, it has generally been speculated that the low friction of most carbon films, including DLC and diamond, are largely due to the fact that these materials are chemically inert, hence, they exert very little adhesive force during sliding against other materials. Other mechanisms, such as micrographitization [28-30] and formation of transfer layers [19,22,31] on mating surfaces, have also been proposed to explain the ultralow friction coefficients of DLC films. 
It is important to remember that most of these hypotheses are based on observations made on a specific DLC film tested under a very specific condition. The family of DLC coatings is rather large $[4,32]$ and, depending on deposition method and/or condition, more diamondlike or more- graphitelike films may be produced. Furthermore, highly hydrogenated or totally hydrogen-free films can be produced. All of these factors can, in turn, affect the friction and wear performance of the DLC films. Therefore, the proposed friction mechanisms should not be regarded as applicable to all carbon films that we call DLC.

From our friction tests in dry nitrogen, it is clear that DLC films grown in a methane plasma provide the lowest friction coefficient (0.014 at steady-state), whereas films grown in an acetylene plasma provide the highest friction coefficient (see Figs. 1 and 2). The films grown in other gases fall between methane- and acetylene- grown films in terms of their frictional characteristics. As shown in Fig. 2, the friction coefficient of an ethane-grown film is much lower than the friction coefficient of a film grown in acetylene plasma.

The wear resistance of DLC films correlates well with their friction performance. As can be deduced from Figs. 1 and 3, films with higher friction coefficients suffer higher wear rates. The difference between wear rates of balls coated with methane-grown DLC and those coated with acetylene-grown DLC films is nearly two orders of magnitude (i.e., $9 \times 10^{-9} \mathrm{~mm}^{3} / \mathrm{N} . \mathrm{m}$ for methane-grown film vs. $7.5 \times 10^{-7} \mathrm{~mm}^{3} / \mathrm{N}$.m for acetylene-grown film).

Clearly, the most apparent difference between films that exhibit significantly different friction and wear performance in dry nitrogen is the difference in the hydrogen-to-carbon $(\mathrm{H} / \mathrm{C})$ ratios of the source gases. Methane has four $\mathrm{H}$ atoms for each $\mathrm{C}$ whereas acetylene has one. In the case of ethane, the ratio is 3 and for ethylene, the ratio is 2 . The friction and wear test results in Figs. 1 and 3 suggest that DLC films produced in source gases with higher $\mathrm{H} / \mathrm{C}$ ratios exhibit superior friction and wear performance. 
The large disparity in the friction and wear performance of films produced from various source gases may be caused by several factors. It is logical to think that films produced in an acetylene plasma are much poorer in hydrogen than films produced in a methane plasma. As a consequence, the films derived from acetylene may have been more graphitelike than the films derived from methane. As we know, hydrogen in DLC films acts as a promoter/stabilizer of the $\mathrm{sp}^{3}$-bonded carbon phase $[1,4]$. When hydrogen is low, the amount of $\mathrm{sp}^{3}$-bonded carbon precursors is expected to be low. Hence, these films will be more graphitic or will transform to graphite more easily under the high mechanical and thermal loadings of dry sliding contacts. Therefore, the reason for the high and erratic frictional behavior of acetylene-grown films in dry nitrogen may be that these films were more graphitelike. Graphite works best in moist air, but does not really provide low friction in dry air or nitrogen.

We believe that the excellent friction and wear behavior of films derived from methane and ethane may be due, to the fact that they contain more hydrogen in their structures than the acetylene- and ethylene-grown films. As stated earlier, higher hydrogen concentration in DLC films can have a stabilizing effect on the $\mathrm{sp}^{3}$-bonded carbon form [1]. As a result, during sliding tests, these films act more like diamond than graphite. Furthermore, as reported by several researchers [33-36], hydrogen is essential to achieve low friction on most carbon-based materials because it can attach and passivate the dangling surface bonds of carbon in diamond, graphite, or fullerenes. Apparently, when the dangling bonds are passivated, the adhesion component of friction is drastically reduced. In fact, the low-friction mechanism of diamond is largely attributed to the highly passive nature of its sliding surface [33-35]. When hydrogen and other species are desorbed or removed from the sliding surfaces of diamond and/or graphite (e.g., by ion-beam sputtering and/or high-temperature annealing in vacuum), the friction coefficient increases significantly, presumably because the reactivated dangling bonds cause strong adhesive interactions between the diamond and the counterface ball or pin materials [33-40].

In an effort to further demonstrate the beneficial effect of hydrogen on the frictional behavior 
of DLC films, we ran a series of sliding tests on films that were grown in gas discharge plasmas that consisted of pure methane, pure methane $+25 \%$ hydrogen, and pure methane $+50 \%$ hydrogen. The counterface ball ( $9.55 \mathrm{~mm}$ in diameter) was made of M50 steel. Figure 4 shows the results of these tests. It is clear from the figure that there is a close correlation between the steady-state friction coefficients and the amount of hydrogen in the gas discharge plasmas. Specifically, the higher the amount of hydrogen in the gas discharge plasma the lower the friction coefficient of the resultant film. Also, the frictional trace becomes much smoother as the amount of hydrogen increases in the source gas plasmas.

Briefly, we believe that hydrogen plays an important role in the frictional behavior of DLC films. Films grown in methane contain more hydrogen in their microstructures than films grown in other source gases, so these films were more saturated with a species that pacifies the dangling bonds of carbon atoms that can otherwise cause high adhesion or friction during sliding.

\section{CONCLUSIONS}

From the friction and wear data presented in this study, it is clear that a significant difference exists in the tribological properties of DLC films derived from acetylene, ethylene, ethane, and methane. The methane-produced DLC films exhibited the lowest friction coefficient and wear of all the DLCs tested. We think that these differences in friction and wear are most likely due to the much higher $\mathrm{H} / \mathrm{C}$ ratio in the source gases from which the DLC films were derived. Additional tests demonstrated that the DLC films grown in methane hydrogen plasmas achieved much improved friction coefficient and wear performance, thus further confirming that hydrogen plays an important role in the friction and wear performance of DLC films.

\section{ACKNOWLEDGMENTS}

This work was supported by the U.S. Department of Energy under Contract W-31-109-Eng-38. 


\section{REFERENCES}

1. H. Tsai and D. B. Bogy, J. Vac. Sci. Technol., A5 (1987) 3287.

2. J. F. Braza and T. S. Sudarshan, "Tribological Behavior of Diamond and Diamondlike Carbon Films: Status and Prospects," in Surface Modification Technologies V (T. S. Sudarshan and J. F. Braza, eds.), The Institute of Materials (1992), p. 801.

3. A. Matthews and S. S. Eskildsen, Diamond and Rel. Mat. 3(1994)902.

4. S. Neuville and A. Matthews, MRS Bull., 22 (9)1(997) 22

5. J. J. Cuomo, J. P. Doyle, J. Bruley, and J. C. Liu, Appl. Phys. Lett., 58(1991)1.

6. R. Wei, P. J. Wilbur, A. Erdemir, F. M. Kustas, Surf. Coat. Technol., 51(1992)139

7. C. Weissmantel, K. Bewilogua, K. Breuer, D. Dietrich, U. Ebersbach, H.-J. Erler, B. Rau, and G. Reisse, Thin Solid Films, 96 (1982)31.

8. K. Miyoshi, J. J. Pouch, and S. A. Alterovitz, Mater. Sci. Forum, 52/53 (1989)645.

9. A. A. Voevodin, M. S. Donley, and J. S. Zabinski, Surf. Coat. Technol., 92(1997)42.

10. H. Ronkainen, J. Koskinen, A. Anttila, K. Holmberg, and J.-P Hirvinen, Diamond and Rel. Mat., 1(1992)639.

11. H. Dimgen and C. P. Klages, Surf. Coat. Technol., 49(1991)543.

12. S. J. Harris, A. M. Weiner, and W.-J. Meng, Wear, 211(1997)208.

13. A. K. Gangopadhyay, P. A. Wolermet, M. A. Tamor, and W. C. Wassell, Tribol. Int., 30(1997)9.

14. K. Miyoshi, R. L. C. Wu, and A. Garscadden, Surf. Coat. Technol., 54/55(1992)428.

15. A. Erdemir, M. Switala, R. Wei, and P. Wilbur, Surf. Coat. Technol., 50(1991)17.

16. C. Donnet and A. Grill, Surf. Coat. Technol., 94-95(1997)456.

17. A. Grill, V. Patel, and B. Meyerson, Surf. Coat. Technol., 49(1991)530.

18. H. Ronkainen, J. Koskinen, J. Likonen, S. Varjus, and J. Vihersalo, Diam. Rel. Mater., 3(1994) 1329.

19. A. Erdemir, C. Bindal, G. R. Fenske, P. Wilbur, Tribol. Trans., 39(1996)735.

20. C. Donnet, M. Belin, J. C. Martin, J. M. Martin, A. Grill, and V. Patel, Surf. Coat. Technol., 68-69(1994)626.

2l. C. Donnet, T. Le Mogne, L. Ponsonnet, M. Belin, A. Grill, V. Patel, Tribology Letters, 4 (1998) $259-265$.

22. D. S. Kim, T. E. Fischer, and B. Gallois, Surf. Coat. Technol., 49(1991)537.

23. K. Holmberg, J. Koskinen, H. Ronkainen, J. Vihersalo, J. P. Hirvonen, and J. Likonen, Diamond Films and Technol., 4(1994)113. 
24. A. Erdemir and G. R. Fenske, Tribol. Trans., 39 (1996) 787.

25. A. Erdemir, G. R. Fenske, J. Terry, P. Wilbur, Surf. Coat. Technol., 94-95(1997)525.

26. D. S. Knight and W. B. White, J. Mater. Res., 4 (1989) 385.

27. J. Robertson, Advan. Phys., 35 (1986) 317.

28. Y. Liu, A. Erdemir, and E. I. Meletis, Surf. Coat. Technol., 82 (1996) 48-56.

29. Y. Liu, A. Erdemir, and E. I. Meletis, Surf. Coat. Technol., 86/87(1996)564.

30. A. Erdemir, C. Bindal, and C. Zuiker, Surf. Coat. Technol., 86/87(1996)692.

31. M. A. Tamor and W. C. Vassell, J. Appl. Phys., 76 (1994) 3823.

32. A. Erdemir, F. A. Nichols, X. Z. Pan, R. Wei, and P. Wilbur, Diamond and Rel. Mat., 3 (1993) 119.

33. S. V. Pepper, J. Vac. Sci. Technol., 20 (1982) 643.

34. F. P. Bowden and J. E. Young, Proc. Roy. Soc., London, 208 (1951) 444.

35. M. N. Gardos and B. L. Soriano, J. Mater. Res., 5 (1990) 2599.

36. F. P. Bowden and A. E. Hanwell, Proc. Roy. Soc., London, A295 (1966) 233.

37. H. Zaidi, A. Mezin, A. Nivoit, and J. Lepage, Appl. Surf. Sci., 40 (1989)103.

38. D. Paulmier, H. Zaidi, H. Nery, T. Le Huo and T. Matthia, Surf. Coat. Technol., 62 (1993) 570.

39. K. Miyoshi, J. J. Pouch, and S. A. Alterovitz, Mater. Sci. Forum, 52/53 (1989) 645.

40. A. Grill, V. Patel, and B. S. Meyerson, J. Mater. Res., 5 (1990)2531.

\section{FIGURE CAPTIONS}

Figure 1. Friction coefficients of DLC-coated M50 balls sliding against DLC-coated H13 steel disks in dry nitrogen.

Fig. 2. Friction coefficients of M50 balls sliding against DLC film derived from acetylene and ethane plasmas.

Fig. 3. Wear rates of DLC-coated M50 balls sliding against DLC-coated H13 steel disks in dry nitrogen.

Fig. 4. Friction coefficients of uncoated M50 balls sliding against DLC films produced in pure methane, $75 \%$ methane +25 hydrogen and $50 \%$ methane $+50 \%$ hydrogen plasmas. 


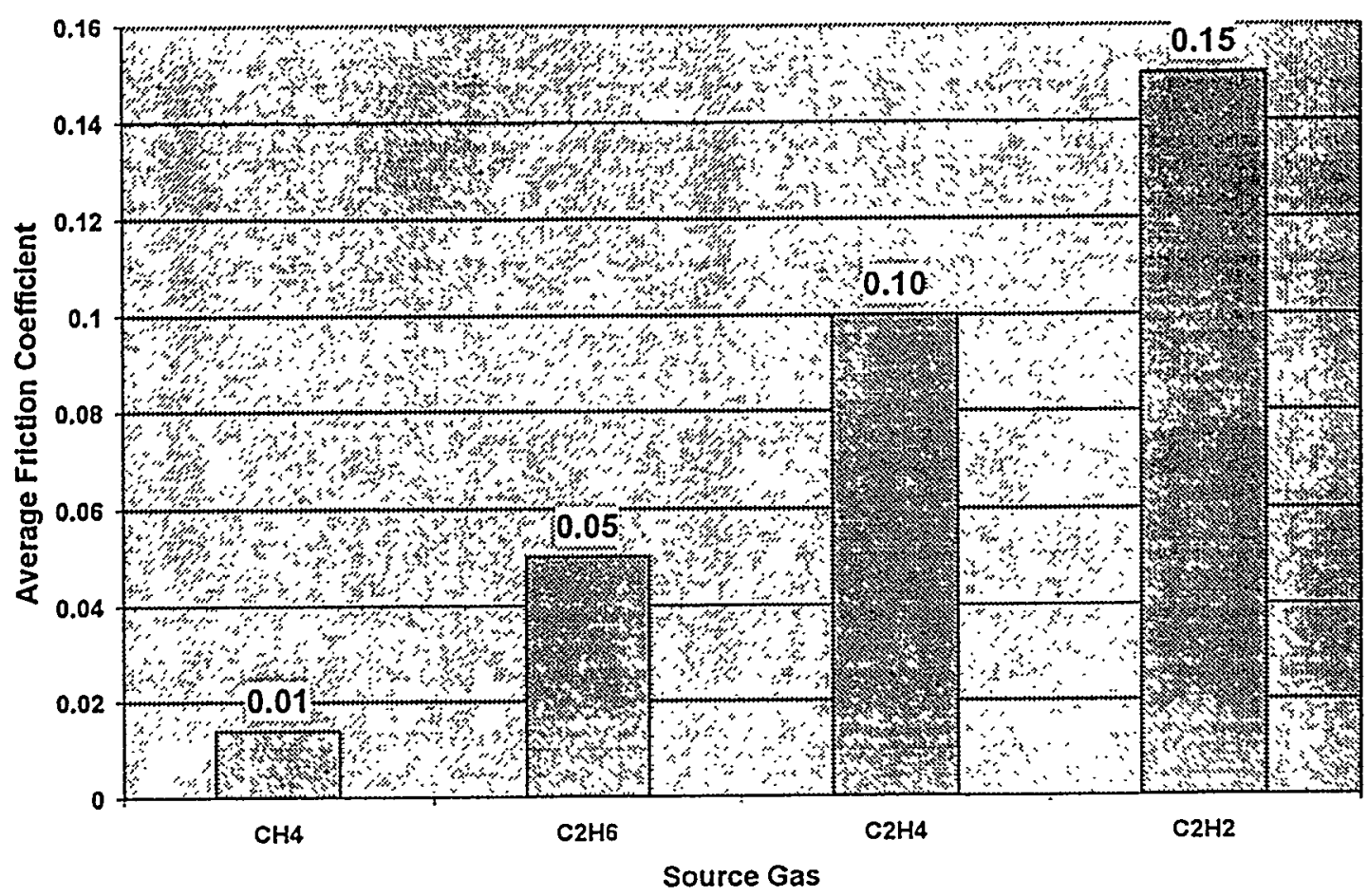

Figure 1. Friction coefficients of DLC-coated M50 balls sliding against DLC-coated H13 steel disks in dry nitrogen.

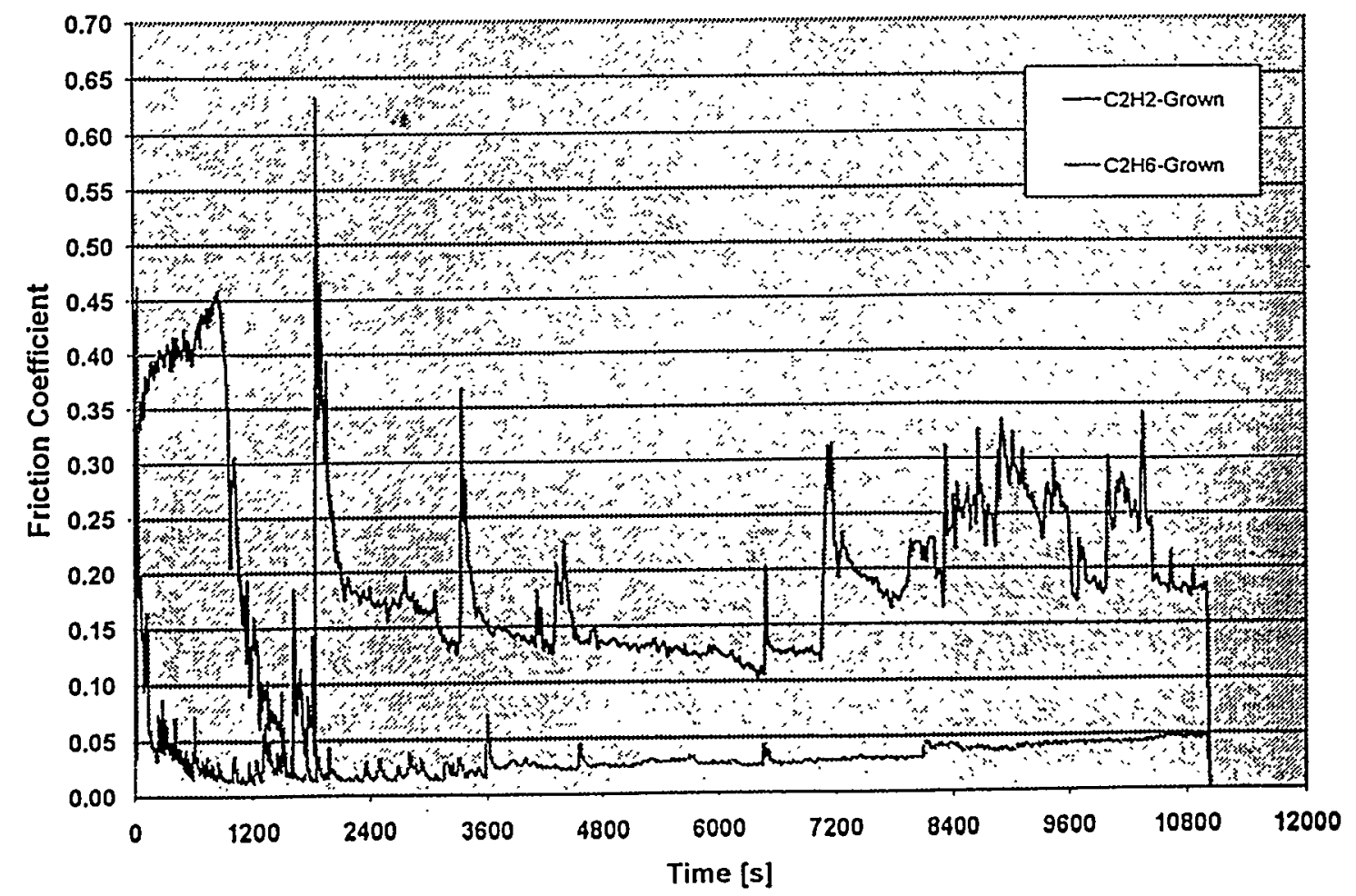


Fig. 2. Friction coefficients of M50 balls sliding against DLC film derived from acetylene and ethane plasmas.

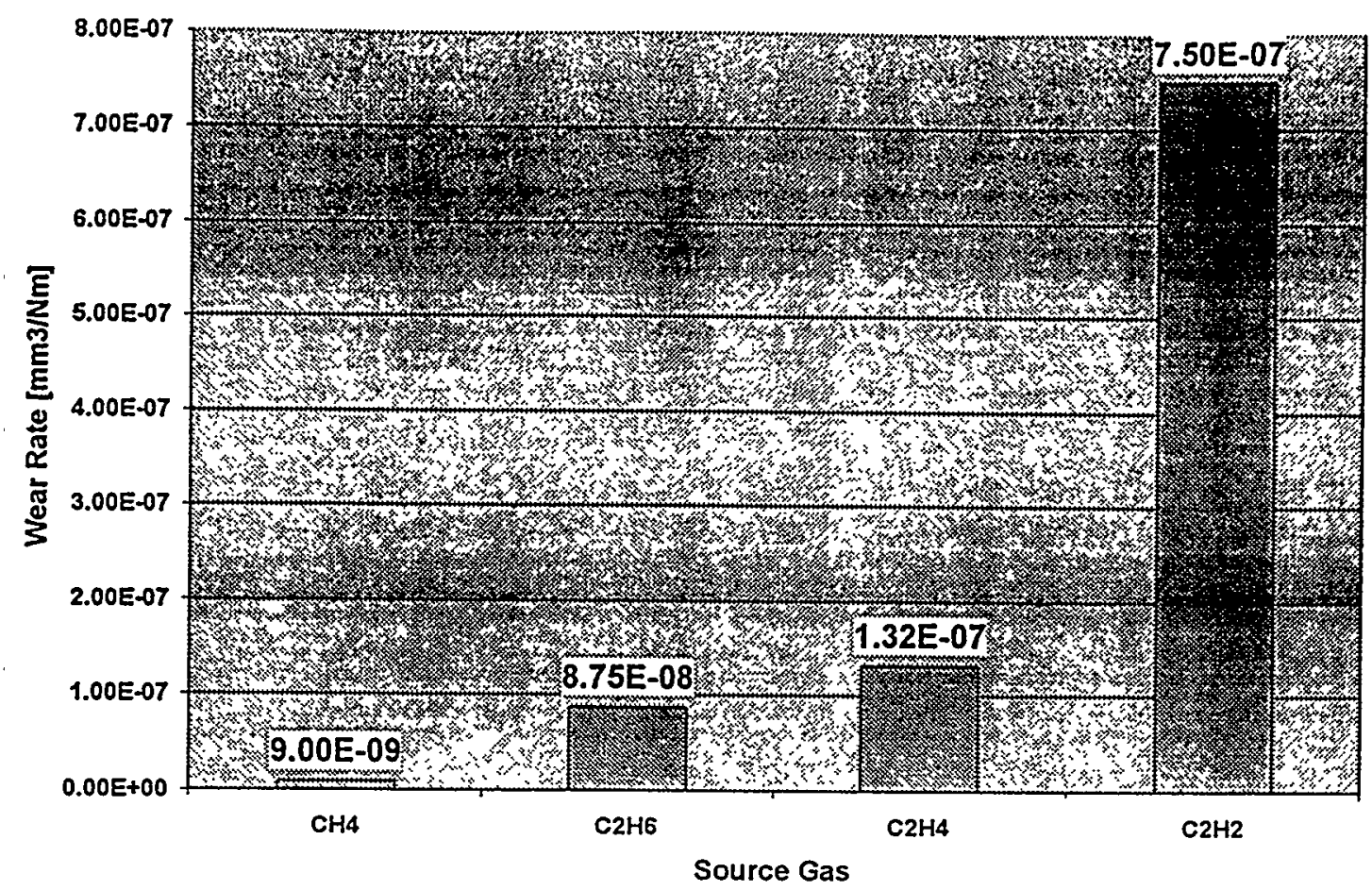

Fig. 3. Wear rates of DLC-coated M50 balls sliding against DLC-coated H13 steel disks in dry nitrogen. 
Methane with different amounts of hydrogen

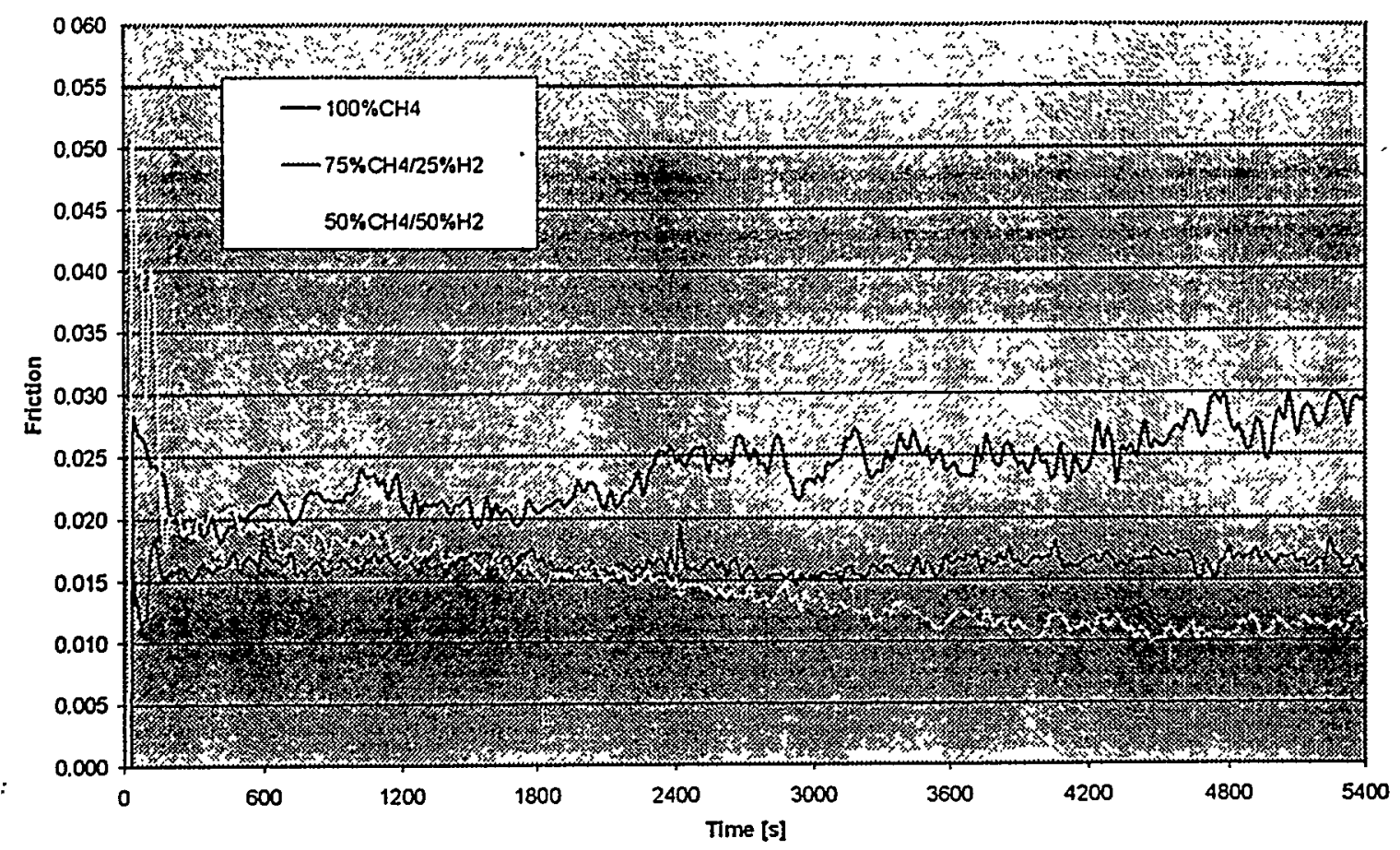

Fig. 4. Friction coefficients of uncoated M50 balls sliding against DLC films produced in pure methane, $75 \%$ methane +25 hydrogen and $50 \%$ methane $+50 \%$ hydrogen plasmas. 